\title{
Comparison of class and continuous pedotransfer functions to generate soil hydraulic characteristics
}

\author{
J.H.M. Wösten ${ }^{\text {a }}$, P.A. Finke ${ }^{\text {a }}$, M.J.W. Jansen ${ }^{\text {b }}$ \\ ${ }^{a}$ DLO-Winand Staring Centre for Integrated Land, Soil and Water Research (SC-DLO), P.O. Box 125, 6700 AC \\ Wageningen, The Netherlands \\ ${ }^{\mathrm{b}}$ DLO-Agricultural Mathematics Group, P.O. Box 100,6700 AC Wageningen, The Netherlands
}

Received 7 April 1994; accepted after revision 5 December 1994

\begin{abstract}
Class pedotransfer functions were used to generate average hydraulic characteristics for distinct soil texture classes. Continuous pedotransfer functions were used to generate soil hydraulic characteristics from the actually measured median of the sand particle size, bulk density and percentages clay, silt and organic matter. Both approaches were used to predict the soil physical input data to calculate five different functional aspects of soil behaviour. The functional aspects were: number of workable days, number of days with adequate soil aeration, elapsed time until $10 \%$ breakthrough of chloride, amount of cadmium leached after one year and amount of Isoproturon leached after one year.

Simulations of water and solute transport were made for 88 profiles which form a statistically representative set of profiles for cover sands in the northeastern part of the Netherlands. The calculated number of workable days did not depend on the type of pedotransfer used. However, the differences between the class and continuous pedotransfer function approach were significant for the other four functional aspects of soil behaviour. For adsorbing cadmium and adsorbing and degradable Isoproturon, differences between the two approaches were statistically significant because they were systematic. However, these differences were so small that they were irrelevant in practice. When to prefer which approach was ambiguous and depended on the functional aspect under consideration. When differences were not significant or irrelevant in practice, the cheaper and easier to use class pedotransfer function approach is preferred over the continuous pedotransfer function approach.
\end{abstract}

\section{Introduction}

Soil hydraulic characteristics are crucial input data for modelling water and solute movement in the unsaturated zone of the soil. Different techniques are available to measure these characteristics both in the laboratory and in the field (Klute and Dirksen, 1986; Green et 
al., 1986). Developments in electronics and computers will advance considerably the measurement procedures and increasingly result in computer driven, stand-alone devices. Notwithstanding these encouraging developments, measurements remain relatively time-consuming and therefore costly (Van Genuchten and Leij, 1992).

As a consequence, the need to make new measurements continues to be critically evaluated considering both the desired accuracy of the hydraulic characteristics and the available financial means to measure them. In this context it is still useful to analyze already existing databases in such a way that predictions of average hydraulic characteristics can be derived. In this way, continuation of investments in new measurements can be limited.

In contrast to direct measurement of hydraulic characteristics, this latter procedure is called an indirect method or pedotransfer function approach in which the hydraulic characteristics are predicted from more easily measured soil data such as texture, organic matter content and bulk density (Bouma and Van Lanen, 1987). Within the pedotransfer functions a subdivision is made in class and continuous pedotransfer functions. A class pedotransfer function predicts the hydraulic characteristics of a texture class such as, for example, loamy sand. A continuous pedotransfer function predicts the hydraulic characteristics using, for example, the actually measured percentages clay, silt and organic matter content.

Generally speaking, class pedotransfer functions are cheap and easy to use because it suffices to identify the texture class to which the soil belongs. At the same time, the obtained accuracy is limited because the approach provides one average hydraulic characteristic for each texture class. Due to ranges in texture within such a class, characteristics for individual soils vary considerably. In comparison, use of continuous pedotransfer functions requires the relatively costly determination of the exact textural composition of a soil. This has the positive effect that the predicted hydraulic characteristics are likely to be more accurate because the texture class can be derived from the textural composition. When using pedotransfer functions, one must realize that this indirect method does not exist without direct methods. This because only measurements create the database from which indirect methods are derived.

In this study, class and continuous pedotransfer functions derived from a database of measured hydraulic characteristics for soils in the Netherlands are used to generate the hydraulic input data for 88 soil profiles. These profiles form a statistical representative set of profiles for a large mapping unit distinguished in an area characterized by eolian sand sediments.

A water and solute transport model is used to calculate five functional aspects of soil behaviour for all profiles. Two of those are physical aspects: number of workable days and number of days with adequate soil aeration. The other three are chemical aspects: elapsed time until $10 \%$ breakthrough of the inert tracer chloride and amount leached after one year of the adsorbing, inert heavy metal cadmium and of the adsorbing, degradable herbicide Isoproturon. This herbicide is chosen because it is commonly used and shows no extreme behaviour. The five functional aspects are calculated using both class and continuous pedotransfer functions to predict the soil hydraulic characteristics. There are no independently measured values available for the simulated functional aspects, therefore the two approaches can only be evaluated on a relative and not on an absolute scale.

The objectives of this study are: 
(i) to demonstrate the establishment of class and continuous pedotransfer functions to generate soil hydraulic characteristics, and

(ii) to compare the use of these two types of pedotransfer functions with respect to five calculated functional aspects of soil behaviour.

\section{Materials and methods}

\subsection{Soils}

The study focused on the mapping unit of the 1:50,000 soil map classified as a sandy, siliceous, mesic Typic Haplaquod (Soil Survey Staff, 1975). This mapping unit occupies $115 \mathrm{~km}^{2}$ and dominates the Pleistocene cover sands in the northeastern part of the Netherlands (Visschers, 1993). The mean highest water table (MHW) in these soils was shallower than $40 \mathrm{~cm}$ while the mean lowest water table (MLW) was deeper than $120 \mathrm{~cm}$. Following a stratified two-stage random sampling design, a set of 88 profile descriptions was collected (Brus and De Gruijter, 1993). As a set these profiles were statistically representative for the cover sands in this part of the country. For each profile values were recorded for rootable depth, MHW and MLW as well as for each soil horizon its depths and the characteristic percentages clay, silt, organic matter and the median of the sand fraction. Map purity of the unit was high, since $93 \%$ of the area is occupied by soils satisfying the definition.

\subsection{Database of measured soil hydraulic characteristics}

Over the years and in a number of different research projects, water retention and hydraulic conductivity characteristics were measured for a large number of soils in the Netherlands.

Hydraulic conductivities were measured using a combination of the following five methods:

(i) the column method for the vertical saturated hydraulic conductivity, $K_{\mathrm{s}}$;

(ii) the crust-test for unsaturated conductivities when the pressure head, $h$, is between 0 and $-50 \mathrm{~cm}$;

(iii) the sorptivity method for conductivities of coarse-textured soils when $h \leq-50 \mathrm{~cm}$;

(iv) the hot-air method for conductivities of medium and fine-textured soils when $h \leq-50$ $\mathrm{cm}$;

(v) the evaporation method for hydraulic conductivities when $h$ is between 0 and -800 $\mathrm{cm}$.

Soil water retention curves were obtained by slow evaporation of wet, undisturbed samples in the laboratory. Pressure heads were measured periodically using transducertensiometers while at the same time subsamples were taken to determine water contents. Alternatively, water contents were also determined by weighing the total sample. Both methods yield points relating $h$ to the water content, $\theta$. Water contents corresponding with pressure heads lower than $-800 \mathrm{~cm}$ were obtained by conventional methods using air pressure. In some methods for relatively fine-textured soils, a staining technique was applied to record the effects of horizontal cracks on the upward flux of water from the water table 

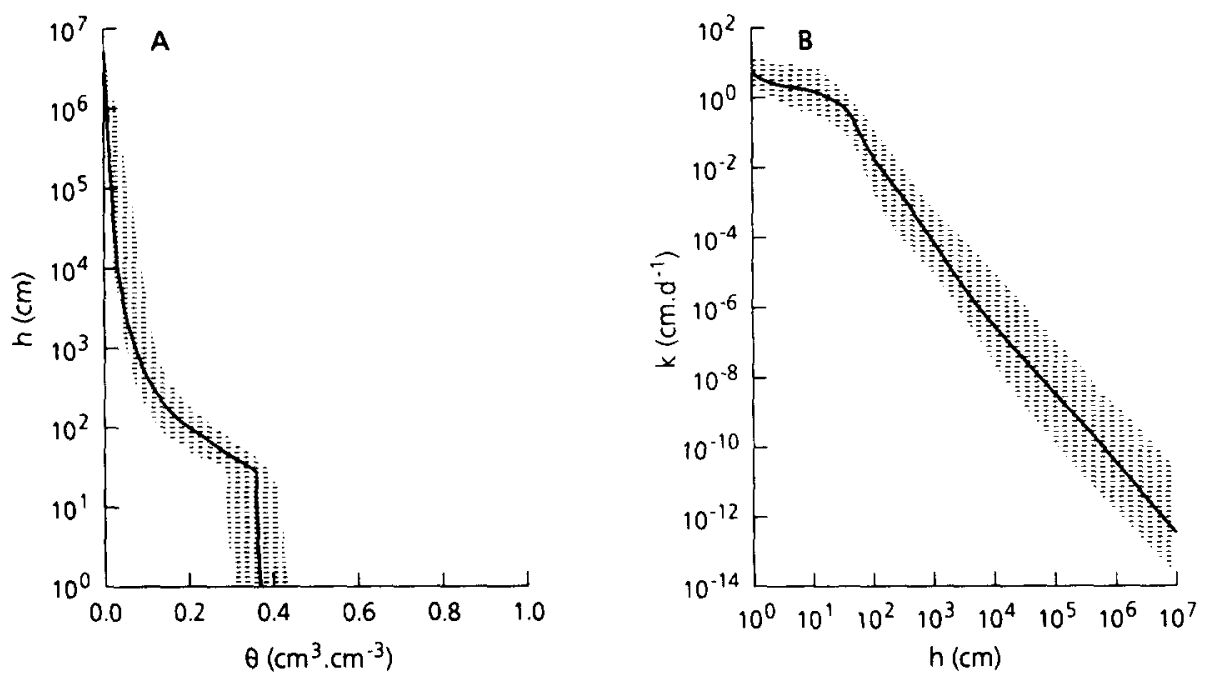

Fig. 1. Geometric mean of the water retention (A) and hydraulic conductivity (B) characteristics for topsoils with the sand textural class.

to the root zone. For details on the majority of the applied measurement techniques reference is made to Stolte et al. (1992).

The effort to measure the hydraulic characteristics for a variety of soils resulted in the establishment of a database of 620 measured characteristics.

\subsection{Generating class pedotransfer functions}

Class pedotransfer functions were established by classifying the soils for which the hydraulic characteristics were measured according to soil texture (as used by the Netherlands Soil Survey Institute), and type of horizon, being either topsoil (A horizon) or subsoil ( $\mathrm{B}$ and $\mathrm{C}$ horizons). In the classification procedure 18 different texture classes were distinguished for both the topsoils and subsoils. After grouping of the measurements in the appropriate texture class, geometric means of the characteristics were calculated for each texture class because the $K$ and $\theta$ values at different $h$ values were approximately lognormally distributed (Wösten et al., 1994). Due to relatively wide ranges within the defined texture classes the individual characteristics within each class show considerable variability. As a set, the averaged characteristics form a unique database covering a broad spectrum of soils in the Netherlands, which was successfully used in numerous simulation studies at regional and national scale. Because average hydraulic characteristics for a texture class are presented they are referred to as class pedotransfer functions. Fig. 1 shows the hand-drawn geometric means of hydraulic characteristics for a topsoil horizon in the sand textural class, having $<10 \%$ clay + silt. The shaded area in this figure represents the variation in individual hydraulic characteristics used to calculate the average characteristic.

Class pedotransfer functions for soils distinguished in the USA were presented by Clapp and Hornberger (1978), and De Jong (1982) presented them for Canadian soils.

To facilitate the efficient use of the calculated characteristics in simulation models, they were described analytically. Various equations are available to parameterize the hydraulic 
characteristics. In this study the volumetric soil water content, $\theta$, and the hydraulic conductivity, $K$, as functions of the pressure head, $h$, were described with the following equations (Van Genuchten, 1980):

$$
\begin{aligned}
& \theta(h)=\theta_{\mathrm{r}}+\frac{\theta_{\mathrm{s}}-\theta_{\mathrm{r}}}{\left(1+|\alpha h|^{n}\right)^{1-1 / n}} \\
& K(h)=K_{\mathrm{s}} \frac{\left[\left(1+|\alpha h|^{n}\right)^{1-1 / n}-|\alpha h|^{n-1}\right]^{2}}{\left(1+|\alpha h|^{n}\right)^{(1-1 / n)(l+2)}}
\end{aligned}
$$

In these equations the subscripts $\mathrm{r}$ and $\mathrm{s}$ refer to residual and saturated values, while $\alpha, n$ and $l$ are parameters which determine the shape of the curve. The residual water content, $\theta_{\mathrm{r}}$, refers to the water content where the gradient $\mathrm{d} \theta / \mathrm{d} h$ becomes zero $(h \rightarrow-\infty)$. In practice, $\theta_{\mathrm{r}}$ is the water content at some large negative value of the soil water pressure head. The parameter $\alpha\left(\mathrm{cm}^{-1}\right)$ equals approximately the inverse of the pressure head at the inflection point where $\mathrm{d} \theta / \mathrm{d} h$ has its maximum value. The dimensionless parameter $n$ determines the rate at which the $S$-shaped retention curve turns towards the ordinate for large negative values of $h$, thus reflecting the steepness of the curve. The dimensionless parameter $l$ determines the slope of the hydraulic conductivity curve in the range of more negative values of $h$.

The flexibility of the equations in generating different shapes of the $\theta(h)$ and $K(h)$ relationships was demonstrated by a number of researchers (e.g. Hopmans and Overmars, 1986; Wösten and Van Genuchten, 1988). The nonlinear least-squares optimization program RETC ( Van Genuchten et al, 1991) has been used to estimate the unknown parameters $\left(\theta_{\mathrm{r}}, \theta_{\mathrm{s}}, \alpha, n, l\right.$ and $\left.K_{s}\right)$ in both equations simultaneously from measured soil water retention and hydraulic conductivity data. In the optimization procedure sums of squares of differences between measured and predicted water contents and between measured and predicted logarithmic transformed hydraulic conductivities were minimized. In the most general case, all parameters $\theta_{\mathrm{r}}, \theta_{\mathrm{s}}, \alpha, n, l$ and $K_{s}$ were optimized. However, due to the limited information at the dry end of the water retention curve the parameter $\theta_{\mathrm{r}}$ was fixed at a value of 0.01 .

\subsection{Generating continuous pedotransfer functions}

To establish continuous pedotransfer functions the above described procedure has been followed for the parameterization of all individually measured hydraulic characteristics. After parameterization, linear regression was used to investigate the dependency of each of the model parameters on more easily measured basic soil properties. To comply with a number of physical boundary conditions, transformed model parameters were used in the regression analysis rather than the original parameters.

For sandy soils the imposed boundary conditions were: $K_{\mathrm{s}}>0, \alpha>0, n>1$ and $-2<l<+2$. As a consequence, the parameters were transformed as follows: $K_{\mathrm{s}}^{*}=\ln \left(K_{\mathrm{s}}\right)$, $\alpha^{*}=\ln (\alpha), n^{*}=\ln (n-1)$ and $l^{*}=\ln [(l+2) /(2-l)]$. The following basic soil properties were used as independent variables: $C S$, percent clay + silt (i.e. percent $<50 \mu \mathrm{m}$ ); OM, percent organic matter; D, bulk density; M50, median sand particle size, and also the discrete variable topsoil or subsoil. 
For loamy and clayey soils, the physical boundary condition for parameter $l$ would have been different while the independent variable percent clay + silt would have been replaced by percent clay. Since this study was restricted to sandy soils in the northeastern part of the Netherlands, the case for loamy and clayey soils is not further discussed.

Linear, reciprocal and exponential functions of the basic soil properties were used in the regression analysis, while possible interactions were also investigated. As a consequence, the resulting regression model or continuous pedotransfer function consists of various basic soil properties and their interactions. This model was selected with the subset selection method of Furnival and Wilson (1974).

The resulting continuous pedotransfer functions for the sandy soils are:

$$
\begin{aligned}
& K_{\mathrm{s}}^{*}=9.5-1.471 \mathrm{D}^{2}-0.688 \mathrm{OM}+0.0369 \mathrm{OM}^{2}-0.332 \ln (\mathrm{CS}) \quad\left(R^{2}=32 \%\right) \\
& \alpha^{*}=146.9-0.0832 \mathrm{OM}-0.395 \text { topsoil }-102.1 \mathrm{D}+22.61 \mathrm{D}^{2} \\
& -70.6 \mathrm{D}^{-1}-1.872 \mathrm{CS}^{-1}-0.3931 \ln (\mathrm{CS}) \quad\left(R^{2}=53 \%\right) \\
& n^{*}=1092+0.0957 \mathrm{CS}+1.336 \mathrm{M} 50-13,229 \mathrm{M} 50^{-1}-0.001203 \mathrm{M} 50^{2} \\
& -234.6 \ln (\mathrm{M} 50)-2.67 \mathrm{D}^{-1}-0.115 \mathrm{OM}^{-1}-0.4129 \ln (\mathrm{OM}) \\
& -0.0721 \mathrm{D} \times \mathrm{CS} \quad\left(R^{2}=63 \%\right) \\
& l^{*}=0.797-0.591 \mathrm{OM}+0.0677 \mathrm{OM}^{2}+0.573 \text { subsoil } \quad\left(R^{2}=42 \%\right) \\
& \theta_{\mathrm{s}}=-13.6-0.01533 \mathrm{CS}+0.0000836 \mathrm{CS}^{2}-0.0973 \mathrm{CS}^{-1}+0.708 \mathrm{D}^{-1}
\end{aligned}
$$

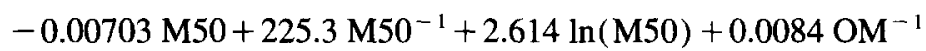

$$
\begin{aligned}
& +0.02256 \ln (\mathrm{OM})+0.00718 \mathrm{D} \times \mathrm{CS} \quad\left(R^{2}=71 \%\right)
\end{aligned}
$$

After prediction of the transformed model parameters with these functions, the hydraulic characteristics were obtained by back-transformation to the original model parameters. A comparable approach to derive continuous pedotransfer functions for different soils has been used by, for instance, Ghosh (1980), Cosby et al. (1984), Rawls and Brakensiek (1985), Saxton et al. (1986) and Vereecken et al. (1989, 1990). Recently, Tietje and Tapkenhinrichs (1993) gave an excellent overview of the various continuous pedotransfer functions available to predict the water retention curve.

\subsection{Simulation of the five functional aspects}

Soil water flow was simulated with the SwACROP model (Feddes et al., 1988), which is a one-dimensional, finite difference model that describes transient, unsaturated water flow in a heterogeneous soil/root system that may or may not be under groundwater influence. Solute transport was simulated with the TRANSOL model (Rijtema and Kroes, 1991).

Soil physical input data for every horizon of the 88 soil profiles that form a representative set for the cover sands in the northeastern part of the Netherlands, were obtained using both the class and continuous pedotransfer function approach. Recorded soil data for every horizon allowed for the estimation of the soil hydraulic characteristics with the two approaches. Estimations of bulk densities were obtained using the linear regression model 
established by Krabbenborg et al. (1983) for these soils. In this regression model, percent organic matter (OM) and the discreet variable topsoil or subsoil are the regressed variables. Soil input data needed by the solute transport model are the percent organic matter (OM), the $\mathrm{pH}$ (estimated from the type of soil horizon) and sorption and decomposition parameters. The latter two parameters were both derived from literature.

Boundary conditions for the SWACROP model are daily values of potential evapotranspiration, precipitation and water table depth. Potential evapotranspiration and precipitation were measured at a weather station in the central part of the study area. Daily values of the water table depth at each of the 88 profile locations were estimated using the MHW, MLW and a measured value from a characteristic time series. Chemical upper boundary conditions were satisfied by surface application at the first day of simulation of $1.0 \mathrm{~kg} \mathrm{ha}^{-1}$ chloride, $0.3 \mathrm{~kg} \mathrm{ha}^{-1}$ cadmium and $1.5 \mathrm{~kg} \mathrm{ha}^{-1}$ Isoproturon. Initial concentrations were set to 0 . For further details on how water and solutes have been simulated in this study reference is made to Finke et al. (1995).

Based on a yearly precipitation surplus that is close to the average surplus over many years, 1980 was chosen as the year for which simulations were performed. Calculations were made for a bare soil for a period of 18 months from 1 October 1979 till 1 April 1981. The studied physical and chemical functional aspects of soil behaviour were:

(i) the number of workable days, defined as the number of days between 15 March and 15 May 1980 during which the pressure head, $h$, at $5 \mathrm{~cm}$ below the soil surface was $\leq-70 \mathrm{~cm}$

(ii) the number of days with sufficient aeration defined as the number of days in the same time period with an air-filled porosity at $5 \mathrm{~cm}$ depth $\geq 0.1 \mathrm{~cm}^{3} \mathrm{~cm}^{-3}$;

(iii) the elapsed time until $10 \%$ breakthrough of the inert tracer chloride;

(iv) the amount leached after one year of the adsorbing, inert contaminant cadmium;

(v) the amount leached after one year of the adsorbing, degrading herbicide Isoproturon.

The threshold values of $h \leq-70 \mathrm{~cm}$ and air-filled porosity $\geq 0.1 \mathrm{~cm}^{3} \mathrm{~cm}^{-3}$ used to calculate the number of workable days and the number of days with sufficient aeration respectively, proved to be practical threshold values for Dutch conditions (Van Wijk and Feddes, 1986). Breakthrough of the three solutes was calculated for an imaginary plane at $40 \mathrm{~cm}$ below the soil surface. It was considered that solutes which passed this plane are lost for plant uptake and eventually will migrate to the groundwater.

\section{Results and discussion}

Based on the calculated functional aspects for each profile, an areal weighted average was calculated for the whole $115 \mathrm{~km}^{2}$ occupied by the mapping unit. Table 1 shows the means and standard errors for the area as a whole of the calculated five functional aspects of soil behaviour. Differences in results using class and continuous pedotransfer functions were statistically tested using a $t$-test on differences with paired samples taking into account the applied sampling design.

Fig. 2A shows the results of the number of workable days in the 62 day period from 15 March till 15 May 1980 both calculated with a class and continuous pedotransfer function to predict the soil hydraulic characteristics. The figure shows that results obtained with the 
Table 1

Areal weighted values for five functional aspects of soil behaviour calculated for 88 soil profiles using both class and continuous pedotransfer functions to predict soil hydraulic characteristics

\begin{tabular}{|c|c|c|c|c|c|c|c|}
\hline \multirow[t]{2}{*}{ Functional aspect } & \multicolumn{2}{|c|}{$\begin{array}{l}\text { Continuous pedo-transfer } \\
\text { function }\end{array}$} & \multicolumn{2}{|c|}{$\begin{array}{l}\text { Class pedo-transfer } \\
\text { function }\end{array}$} & \multicolumn{3}{|c|}{ Test on differences } \\
\hline & $\mathrm{m}$ & s.e. & m & s.e. & $\mathrm{m}$ & s.e. & $\begin{array}{l}95 \% \text { confidence } \\
\text { limits }\end{array}$ \\
\hline Workable days & 57.9 & 0.8 & 57.8 & 0.8 & -0.1 & 0.35 & $(-0.9 ; 0.54)$ \\
\hline $\begin{array}{l}\text { Days with good } \\
\text { aeration }\end{array}$ & 53.8 & 1.8 & 60.8 & 0.5 & 7.0 & 1.44 & $(4.1 ; 9.9)$ \\
\hline $\begin{array}{l}\text { Days elapsed until } \\
10 \% \text { chloride } \\
\text { breakthrough }\end{array}$ & 40.5 & 0.9 & 38.5 & 0.8 & -2.0 & 0.44 & $(-2.9 ;-1.1)$ \\
\hline $\begin{array}{l}\text { Log leaching mass } \\
\text { cadmium }\end{array}$ & -8.50 & 0.12 & -8.48 & 0.12 & \multicolumn{3}{|c|}{$0.020 .004(0.01 ; 0.03)$} \\
\hline $\begin{array}{l}\text { Log leaching mass } \\
\text { Isoproturon }\end{array}$ & -5.30 & 0.24 & -5.28 & 0.24 & \multicolumn{3}{|c|}{$0.020 .008(0.00 ; 0.03)$} \\
\hline
\end{tabular}

$\mathrm{m}=$ mean value, s.e. $=$ standard error.

two approaches agreed generally well. For the majority of the 88 soil profiles more than 55 days in the considered period were workable. In this case differences between the two approaches were not significant (Table 1). The same result is obtained when the threshold value is changed from $h \leq-70$ to $h \leq-90 \mathrm{~cm}$.

Fig. 2B shows the number of days with good aeration. Using class pedotransfer functions practically all 88 profiles had adequate aeration for more than 55 out of the 62 days. However, when continuous pedotransfer functions are used the number of days with adequate aeration is highly variable and ranges from 0 to 62 days for the 88 profiles. In this case differences between the two approaches were significant (Table 1). It appears that when the number of days with adequate aeration is considered, class pedotransfer functions fail to generate hydraulic characteristics of a sufficiently different nature such that they affect this functional aspect. The same holds when the threshold value for the air-filled porosity is changed from $\geq 0.1$ to $\geq 0.15 \mathrm{~cm}^{3} \mathrm{~cm}^{-3}$. It is concluded that whether the class or continuous pedotransfer function approach will give different results depends on the specific physical functional aspect of soil behaviour under consideration. This result can be understood by the fact that in order to calculate these different functional aspects emphasis is placed on different parts of the soil hydraulic characteristics (i.e. dry versus wet soil)

Fig. 2C shows the number of days elapsed until $10 \%$ breakthrough of the inert tracer chloride. For the majority of the 88 profiles this period was circa 35 to 45 days for both class and continuous pedotransfer functions. However, using continuous pedotransfer functions, the variation among these profiles was slightly larger. Chloride is an inert tracer which does not adsorb or decay, its behaviour is solely governed by the soil hydraulic characteristics, as is the case with workable days, and days with adequate aeration. In this sense, days elapsed until $10 \%$ breakthrough of chloride is comparable to the $10 \%$ travel time of water. Fig. $2 \mathrm{C}$ suggests a fairly good agreement between the two approaches. However, after testing, the differences appear to be statistically significant (Table 1). The continuous 
Class pedotrarisfer function
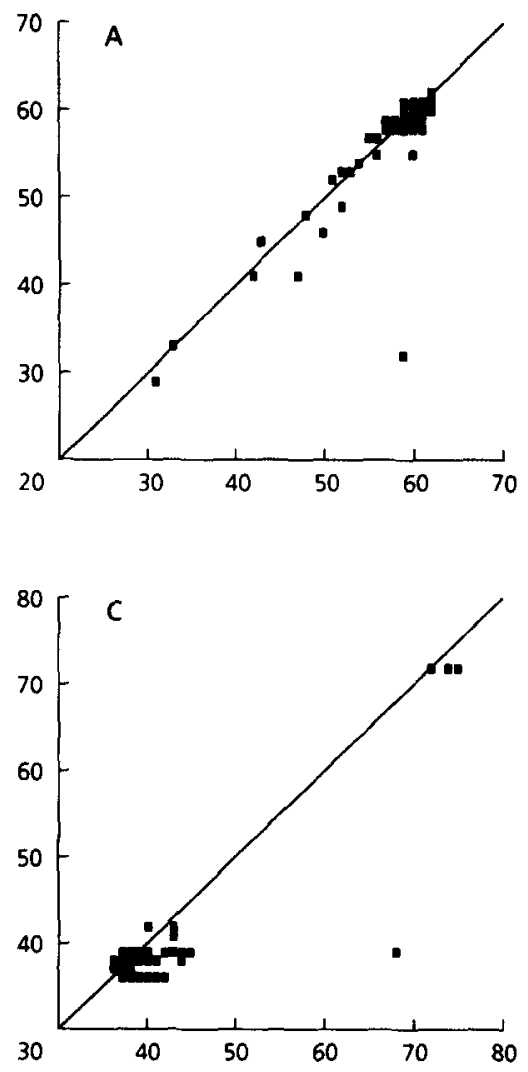

Class pedotransfer function
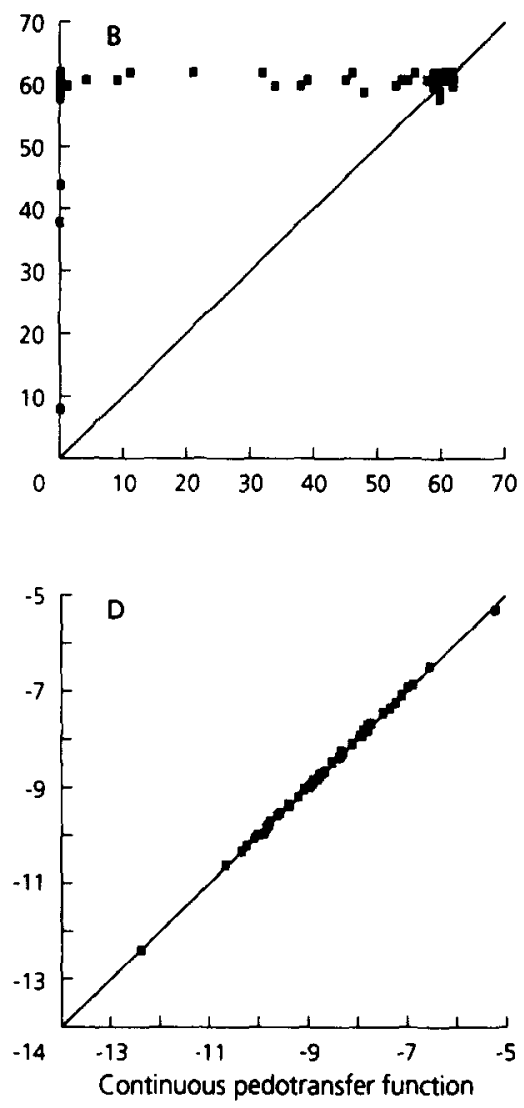

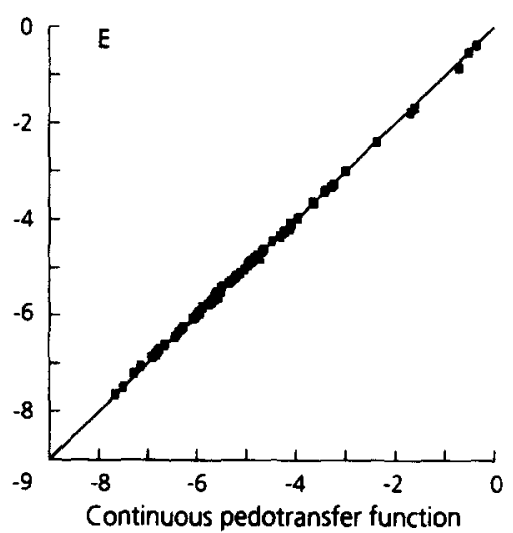

Fig. 2. Relationship between the number of workable days (A), number of days with good aeration (B), number of days elapsed until $10 \%$ breakthrough of chloride $(\mathrm{C})$, logarithm of the leaching mass $(\mathrm{kg} / \mathrm{ha})$ of cadmium (D) and logarithm of the leaching mass $(\mathrm{kg} / \mathrm{ha}$ ) of Isoproturon (E) calculated using class and continuous pedotransfer functions to predict soil hydraulic characteristics. 
pedotransfer function approach results in larger values than the class pedotransfer function approach.

Figs. 2D and 2E show the results for the leached masses of cadmium and of Isoproturon, respectively. Since the results are lognormally distributed, the log-values are presented. In both cases, results obtained with class pedotransfer functions seemed to agree well with those obtained with continuous pedotransfer functions. However, differences between the two approaches are statistically significant (Table 1). The leached amount of cadmium and Isoproturon was always slightly higher when continuous pedotransfer functions were used to estimate the soil hydraulic characteristics. In practice, these differences are so small that they are irrelevant. In the case of solute transport, the adsorption and decay processes apparently diminish the differences that occur when only soil physical processes are active, as is the case for chloride.

\section{Conclusions}

The major conclusion from this study is that when functional aspects of soil behaviour are calculated, results can be different depending on whether class or continuous pedotransfer functions are used to generate the hydraulic input data. Therefore, the choice for the class or continuous pedotransfer function approach is ambiguous and depends on the functional aspect one is interested in. When adsorption and decay processes are active, they diminish the differences that can be attributed to the use of the class or continuous pedotransfer functions.

As a consequence, it remains useful to use existing databases of measured hydraulic characteristics for the establishment of both class and continuous pedotransfer functions. In cases where both approaches yield the same result, easy-to-use and cheap class pedotransfer functions are preferred over the more laborious continuous pedotransfer functions. Independently measured functional aspects of soil behaviour are required to assess the accuracy of the two pedotransfer approaches.

\section{References}

Bouma, J. and Van Lanen, J.A.J., 1987. Transfer functions and threshold values: From soil characteristics to land qualities. In: K.J. Beek et al. (Editors), Quantified Land Evaluation. International Institute Aerospace Surv. Earth Sci. ITC Publ., 6, pp. 106-110.

Brus, D.J. and De Gruijter, J.J., 1993. Design-based versus model-based estimates of spatial means. Theory and application in environmental soil science. Environmetrics, 4: 123-152.

Clapp, R.B. and Hornberger, G.M., 1978. Empirical equations for some soil hydraulic properties. Water Resour. Res., 14: 601-604.

Cosby, B.J., Hornberger, G.M., Clapp, R.B. and Ginn, T.R., 1984. A statistical exploration of the relationship of soil moisture characteristics to the physical properties of soil. Water Resour. Res., 20: 682-690.

De Jong, R., 1982. Assessment of empirical parameters that describe soil water characteristics. Can. Agric. Eng., 24: 65-70.

Feddes, R.A., De Graaf, M., Bouma, J. and Van Loon, C.D., 1988. Simulation of water use and production of potatoes as effected by soil compaction. Potato Res., 31: 255-239. 
Finke, P.A., Wösten, J.H.M. and Kroes, J.G., 1995. Comparison of two approaches to characterize soil mapping unit behaviour in solute transport studies, submitted.

Furnival, G.M. and Wilson, R.W., 1974. Regression by leaps and bounds. Technometrics, 16: 499-511.

Ghosh, R.K., 1980. Estimation of soil-moisture characteristics from mechanical properties of soils. Soil Sci., 130 : $60-63$.

Green, R.E., Ahuja, L.R. and Chong, S.K., 1986. Hydraulic conductivity, diffusivity and sorptivity of unsaturated soils: field methods. In: A. Klute (Editor), Methods of Soil Analysis. Part 1. 2nd ed. Agronomy Monogr. 9. ASA and SSSA, Madison, WI, pp. 771-798.

Hopmans, J.W. and Overmars, B., 1986. Predicting and application of an analytical model to describe soil hydraulic properties. J. Hydrol., 87: 135-143.

Klute, A. and Dirksen, C., 1986. Hydraulic conductivity and diffusivity: laboratory methods. In: A. Klute (Editor), Methods of Soil Analysis. Part 1. 2nd ed. Agronomy Monogr. 9. ASA and SSSA, Madison, WI, pp. 687-734.

Krabbenborg, A.J., Poelman, J.N.B. and Van Zuilen, E.J., 1983. Standaard vochtkarakteristieken van zandgronden en veenkoloniale gronden. Rapport 1680, Stichting voor Bodemkartering, Wageningen, Netherlands.

Rawls, W.J. and Brakensiek, D.L., 1985. Prediction of soil water properties for hydrologic modelling. In: E. Jones and T.J. Ward (Editors), Watershed Management in the Eighties. Proc. Symp. ASCE, Denver, CO. 30 April2 May 1985. ASCE, New York, pp. 293-299.

Rijtema, P.E. and Kroes, J.G., 1991. Chemigation and modelling the behaviour of fertilizers and pesticides. Proc. Expert Consultation on Fertigation/Chemigation Caïro. FAO, Rome, Italy, pp. 107-124.

Saxton, K.E., Rawls, W.J., Romberger, J.S. and Papendick, R.I., 1986. Estimating generalized soil-water characteristics from texture. Soil Sci. Soc. Am. J., 50: 1031- 1036.

Soil Survey Staff, 1975. Soil Taxonomy. A Basic System of Soil Classification for Making and Interpreting Soil Surveys. USDA-SCS, Agric. Handb. 436. U.S. Government Printing Office, Washington, DC.

Stolte, J., Veerman, G.J. and Wopereis, M.C.S., 1992. Manual soil physical measurements, version 2.0. Technical Document 2. DLO-Winand Staring Centre, Wageningen, Netherlands.

Tietje, O. and Tapkenhinrichs, M., 1993. Evaluation of pedo-transfer functions. Soil Sci. Soc. Am. J., 57: 10881095.

Van Genuchten, M.Th., 1980. A closed-form equation for predicting the hydraulic conductivity of unsaturated soils. Soil Sci. Soc. Am. J., 44: 892-898.

Van Genuchten, M.Th. and Leij, F.J., 1992. On estimating the hydraulic properties of unsaturated soils. In: M.Th. van Genuchten, F.J. Leij and L.J. Lund (Editors), Indirect Methods for Estimating the Hydraulic Properties of Unsaturated Soils. Proc. Int. Workshop on Indirect Methods for Estimating the Hydraulic Properties of Unsaturated Soils. Riverside, California, 11-13 October 1989, pp. 1-14.

Van Genuchten, M.Th., Leij, F.J. and Yates, S.R., 1991. The RETC code for quantifying the hydraulic functions of unsaturated soils. EPA/600/2-91/065, U.S. Environmental Protection Agency, Ada, OK.

Van Wijk, A.L.M. and Feddes, R.A., 1986. Simulating effects of soil type and drainage on arable crop yield. In: A.L.M. van Wijk and J. Wesseling (Editors), Agricultural Water Management. Proc. Symp. on Agricultural Water Management, Arnhem, Netherlands, 18-21 June 1985, pp. 97-112.

Vereecken, H., Maes, J., Darius, P. and Feyen, J., 1989. Estimating the soil moisture retention characteristic from texture, bulk density and carbon content. Soil Sci., 148: 389-403.

Vereecken, H., Maes, J. and Feyen, J., 1990. Estimating unsaturated hydraulic conductivity from easily measured soil properties. Soil Sci., 149: 1-12.

Visschers, R., 1993. Upgrading van de Bodemkaart van Nederland, schaal $1: 50$ 000, door steekproeven in kaarteenheden van veldpodzolgronden $\mathrm{Hn} 21-\mathrm{V}$ en Hn21-VI. Rapport 186, DLO Winand Staring Centre, Wageningen, Netherlands.

Wösten, J.H.M. and Van Genuchten, M.Th., 1988. Using texture and other soil properties to predict the unsaturated soil hydraulic conductivity. Soil Sci. Soc. Am. J., 52: 1762-1770.

Wösten, J.H.M., Veerman, G.J. and Stolte, J., 1994. Waterretentie- en doorlatendheidskarakteristieken van bovenen ondergronden in Nederland: De Staringreeks. Technisch Document 18. DLO-Winand Staring Centre, Wageningen. 